Open Access

\title{
Interventional Endoscopic Ultrasonography: Present and Future
}

\author{
Kwang Hyuck Lee and Jong Kyun Lee \\ Department of Medicine, Samsung Medical Center, Sungkyunkwan University School of Medicine, Seoul, Korea
}

\begin{abstract}
The technical advances in endoscopic ultrasonograpy (EUS) and accessories have enabled performing EUS-guided intervention in the pancreas and biliary tract. Many research centers have been performing or investigating EUS-guided drainage, EUS-guided celiac plexus neurolysis and block, EUS-guided anastomosis that includes choledocho-enterostomy and choledocho-gastrostomy, EUS-guided ablation and injection therapy mainly for pancreatic neoplasm, EUS-guided photodynamic therapy and EUS-guided brachytherapy. Some of these are currently clinical applications and others are under investigations in clinical studies or animal models. Further detailed randomized controlled clinical trials and the development of materials will bring us into a new era of therapeutic EUS.
\end{abstract}

Key Words: Endoscopic ultrasonograpy; Intervention; Drainage; Anastomosis; Neurolysis

\section{INTRODUCTION}

Endoscopic ultrasonography (EUS) was developed to observe abdominal organs with a sonic probe located in the nearby gastrointestinal tract. With improvements of sonographic resolution, application of Doppler imaging and the technical progress of endosonograhic accessories, EUS-guided tissue samplings have been conducted more frequently in various clinical situations.

Linear-array therapeutic probes with large working channels have recently been developed. These technical advances enable us to perform EUS-guided intervention in the pancreas and for biliary tract disease in various clinical situations and to investigate new procedures mainly regarding the local control of pancreatic tumors. Moreover, new innovative techniques are under investigation in animal models. In this review, we focus on interventional EUS mainly for diseases of the pancreas and biliary tract.

Received: July 21, 2011 Revised: September 18, 2011

Accepted: September 19, 2011

Correspondence: Jong Kyun Lee

Division of Gastroenterology, Department of Medicine, Samsung Medical Center, Sungkyunkwan University School of Medicine, 50 Irwon-dong, Gangnamgu, Seoul 135-710, Korea

Tel: +82-2-3410-3407, Fax: +82-2-3410-6983, E-mail: jongk.lee@samsung.com

(c) This is an Open Access article distributed under the terms of the Creative Commons Attribution Non-Commercial License (http://creativecommons.org/ licenses/by-nc/3.0) which permits unrestricted non-commercial use, distribution, and reproduction in any medium, provided the original work is properly cited.

\section{EUS-GUIDED PSEUDOCYST DRAINAGE}

Symptomatic and complicated pancreatic pseudocyst can be drained radiologically, surgically or endoscopically by way of gastrocystostomy or duodenocystostomy. In the appropriate setting, EUS-guided drainage of a pancreatic fluid collection can be considered as the treatment of choice to treat pancreatic pseudocysts. A large-channel echoendoscope allows this to be accomplished as a single stage procedure, and so this avoids the need for other therapeutic procedures. It was reported to have a higher success rate and lower morbidity in several comparative studies..$^{1-5}$

Compared to conventional endoscopic drainage, EUS scanning determines the optimal puncture site by identifying the intervening blood vessels and the shortest needle path. This merit allows us to perform drainage even in cases without bulging in the gut lumen. After puncture of this site, the technique is almost the same as conventional endoscopic drainage (Fig. 1). Contrast medium may be injected into the cyst and then a guide wire is positioned. A needle knife, a bougie and a dilatation balloon are introduced through the working channel and they are used to carry out dilatation of the EUS-guided transgastric or transduodenal puncture of the cyst.

Below the guidewire, a nasocystic drain or stent is placed within the cyst to establish complete drainage of the pancreatic pseudocyst or abscess. A 7 Fr plastic stent is commonly inserted due to the size of the working channel of the echo- 


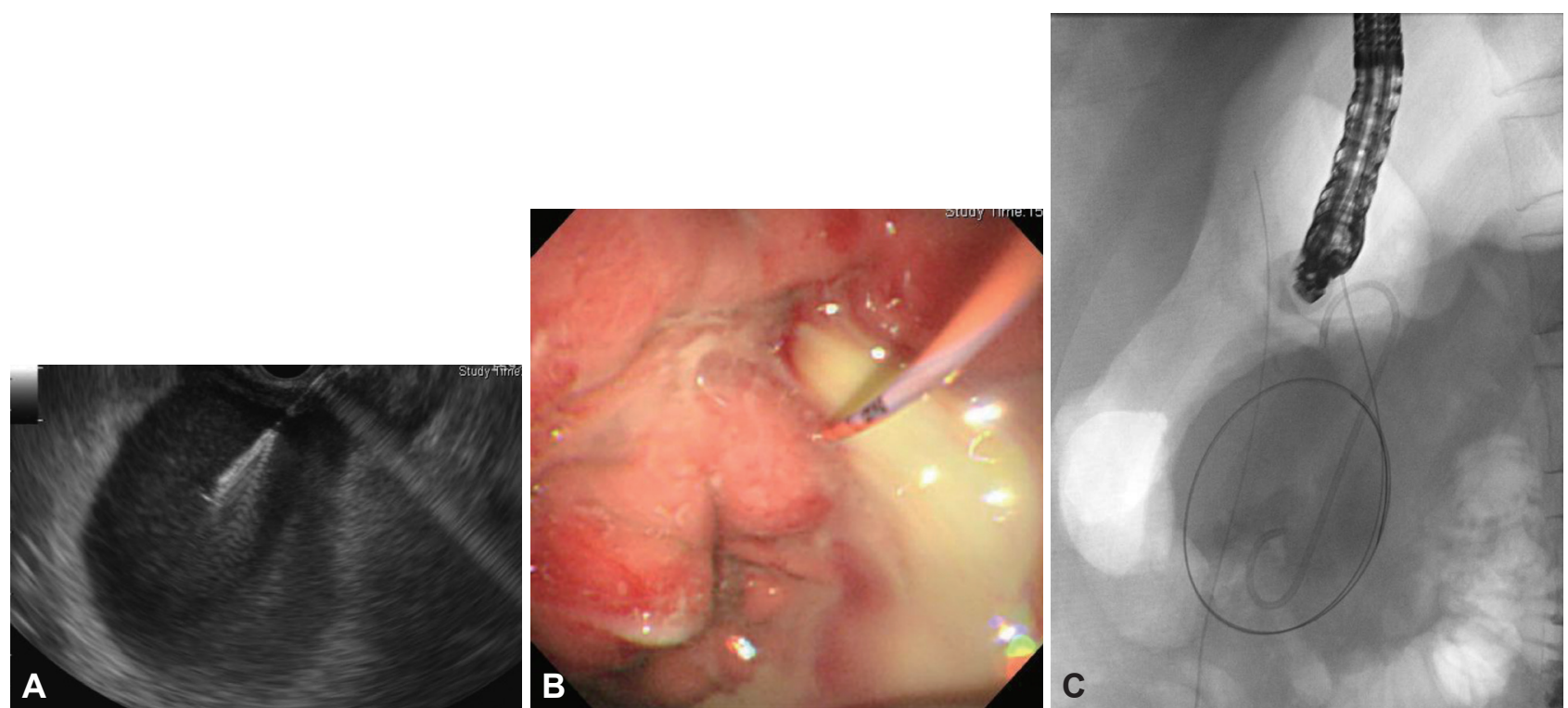

Fig. 1. Endoscopic ultrasonograpy (EUS)-guided pseudocyst drainage. After EUS-guided puncture of pseudocyst (A) and dilatation of puncture site, pus was coming out from infected pseudocyst (B). Endoscopic nasobiliary drainage tube would be inserted over guide wire to irrigate the cyst after a pigtail plastic stent was inserted (C).

endoscope. For efficient drainage, multiple stentings combined with nasocystic drainage are used. Full-covered selfexpandable metal stent insertion is currently under study to obtain a larger drainage route.

\section{EUS-GUIDED CELIAC PLEXUS NEUROLYSIS AND BLOCK}

Celiac plexus neurolysis (CPN) is the injection of absolute alcohol for destroying the sympathetic plexus near the celiac axis to relieve abdominal pain, and this is mainly done in pancreatic cancer patients. Celiac plexus block (CPB) is the injection of steroids to inhibit the pain pathway mainly in patients with chronic pancreatitis. In both procedures, bupivacaine is usually added to relieve initial pain.

EUS-guided CPN can be done via the anterior approach, so it can avoid serious complications brought about by the posterior approach such as parasthesia, paraplegia and pneumothorax. ${ }^{6}$ Another advantage of this technique is to visualize the intervening blood vessels and sometimes the ganglia itself. Real time visualization by EUS enables the injection into the celiac space and sometimes the ganglion itself.

CPN showed alleviation of pain in $70-90 \%$ of the patients with pancreatic cancer. ${ }^{7-9}$ On the other hand, CPB seemed to yield a marginal benefit (a 30-60\% response rate) in chronic pancreatitis patients. A few studies showed EUS-guided CPN provided superior pain relief compared to $\mathrm{CT}$ and fluoroscopy guided celiac plexus ablation therapy.- ${ }^{7-9}$ Further studies are needed for assessing the long-term efficacy of CPN and improving pain relief in patients with chronic pancreatitis.

\section{EUS-GUIDED ANASTOMOSIS: BILIARY AND PANCREATIC DUCT}

Endoscopic retrograde cholangiography (ERCP) is a palliative option for relief of malignant biliary obstruction. It is sometimes impossible due to anatomic and technical difficulties. Surgical or percutaneous biliary drainage are alternative methods, but they have higher morbidity and more discomfort than an endoscopic approach. EUS-guided drainage of the bile duct has recently been studied..$^{10-19}$ Hepaticogastrostomy, choledochoduodenostomy and the rendezvous transpapillary approach are commonly performed according to the anatomic feasibility.

The bulb of the duodenum can be recommended as a puncture site for choledochoduodenostomy in the case of distal common bile duct obstruction because it has some merits (Fig. 2): a close location to the bile duct, it is away from obstructing tumor, there are no intervening major vessels and good stabilization of the echoendoscope. After a convex linear-array echoendoscope guided puncture, a needle knife, bougies and a balloon dilator are used to make and dilate a route. A plastic stent or metal stent is bridged between the dilated bile duct and the duodenal bulb. Hepaticogastrostomy is performed when the left intrahepatic duct is dilated due to perihilar biliary obstruction (Fig. 3). The usual puncture site is the high body of the stomach. The method after a puncture is almost same as choledochoduodenostomy. In the transpapillary approach, EUS-guided placement of a guide-wire through the papilla is performed. After withdrawing the EUS, an endoscopist inserts an ERCP endoscope, grasps the 

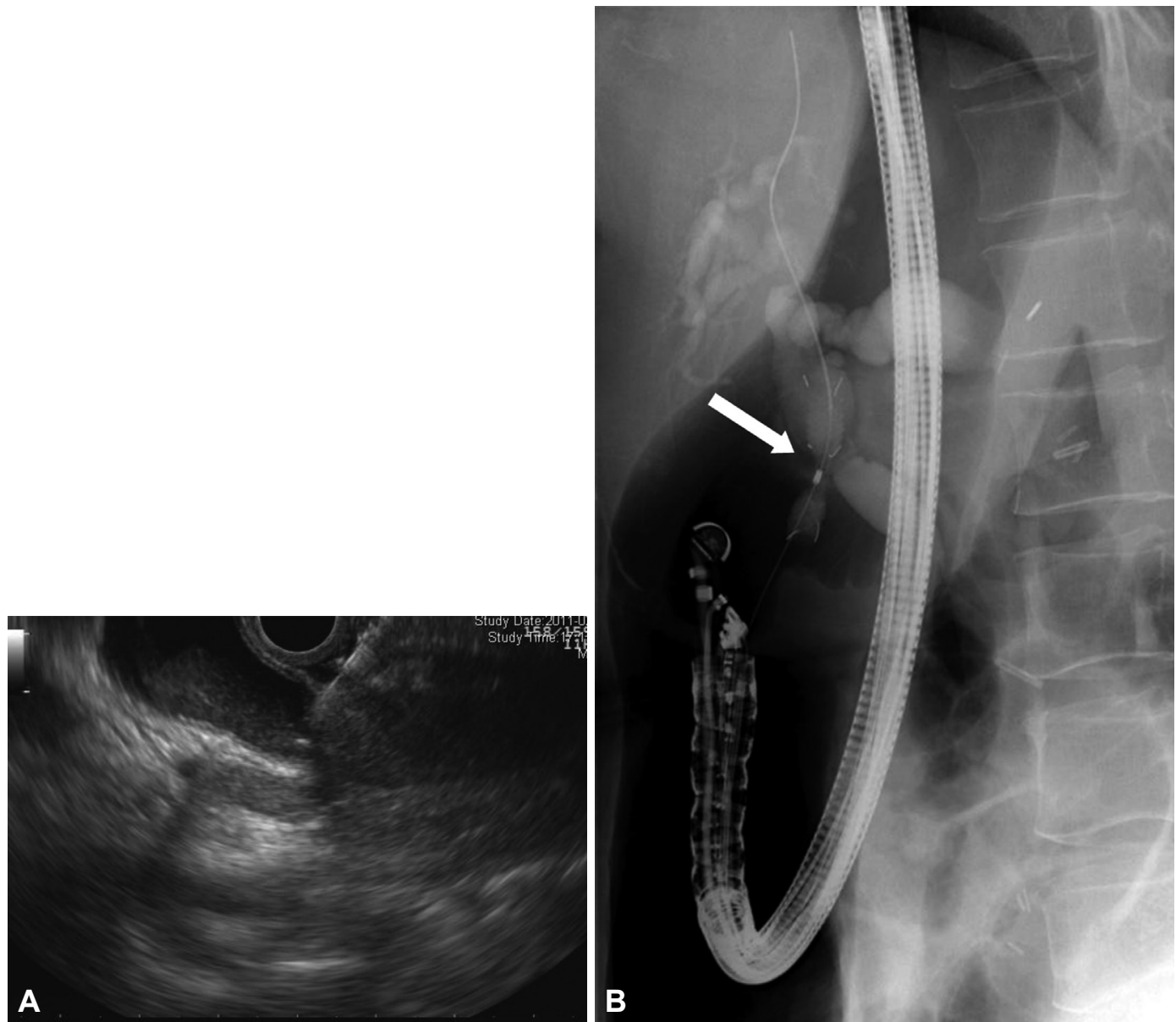

Fig. 2. Choledochoduodenostomy. Due to duodenal partial obstruction, a transpapillary metal stent insertion was impossible. After endoscopic ultrasonograpy-guided puncture of dilated common bile duct (CBD) (A), fully covered metal stent was inserted from duodenal bulb to distal CBD (B).

transpapillary wire with a snare or a biopsy forceps and withdraws it through the operating channel for retrograde introduction of a sphincterotome over the wire.

Around 90\% technical success rates were reported. Several complications such as bile peritonitis, cholangitis, cholecystitis, and pneumoperitoneum were observed and most cases were resolved without significant morbidity. Larger studies and more experience are necessary to define the true riskbenefit profile of this intervention relative to other methods such as percutaneous access.

EUS-guided drainage techniques are also applied to the pancreatic duct with almost same technical approach. ${ }^{16,17,19}$ These have been reported in much more limited numbers of patients. The success rate was a little lower and the complication rate was higher than EUS-guided biliary drainage. It remains technically challenging for the aspect of the difficult puncture of the pancreatic duct and stabilization of the endoscope.

To increase the success rate and decrease the complication rate, the development of EUS-specific accessories is needed, and particularly dedicated stent systems that reduce the potential for bile leak. The forward-viewing linear echoendoscope, which is currently only available as a prototype, may also help to improve the technical feasibility. ${ }^{20}$

\section{EUS-GUIDED CYST ABLATION}

Cyst ablation with ethanol and with or without chemotherapeutic agents showed promising results in some studies. ${ }^{21-25}$ They showed effective decrease or disappearance of cysts after ablation therapy on the radiological evaluation. After 3 months or 12 months, the complete radiological eradication rates were $33 \%$ to $79 \%$ with minimal complications. Multiple endoscopic sessions might increase the rate of image-defined cyst resolution. ${ }^{23}$ However, the long-term outcomes and the effect of preventing malignancy in mucinous cystic lesions have not yet been answered. Moreover, the patients who received ablation therapies and who showed complete eradiation seemed to have no need of any interventions. ${ }^{23}$ Only observation of cysts could be enough for them. It is prudent that 


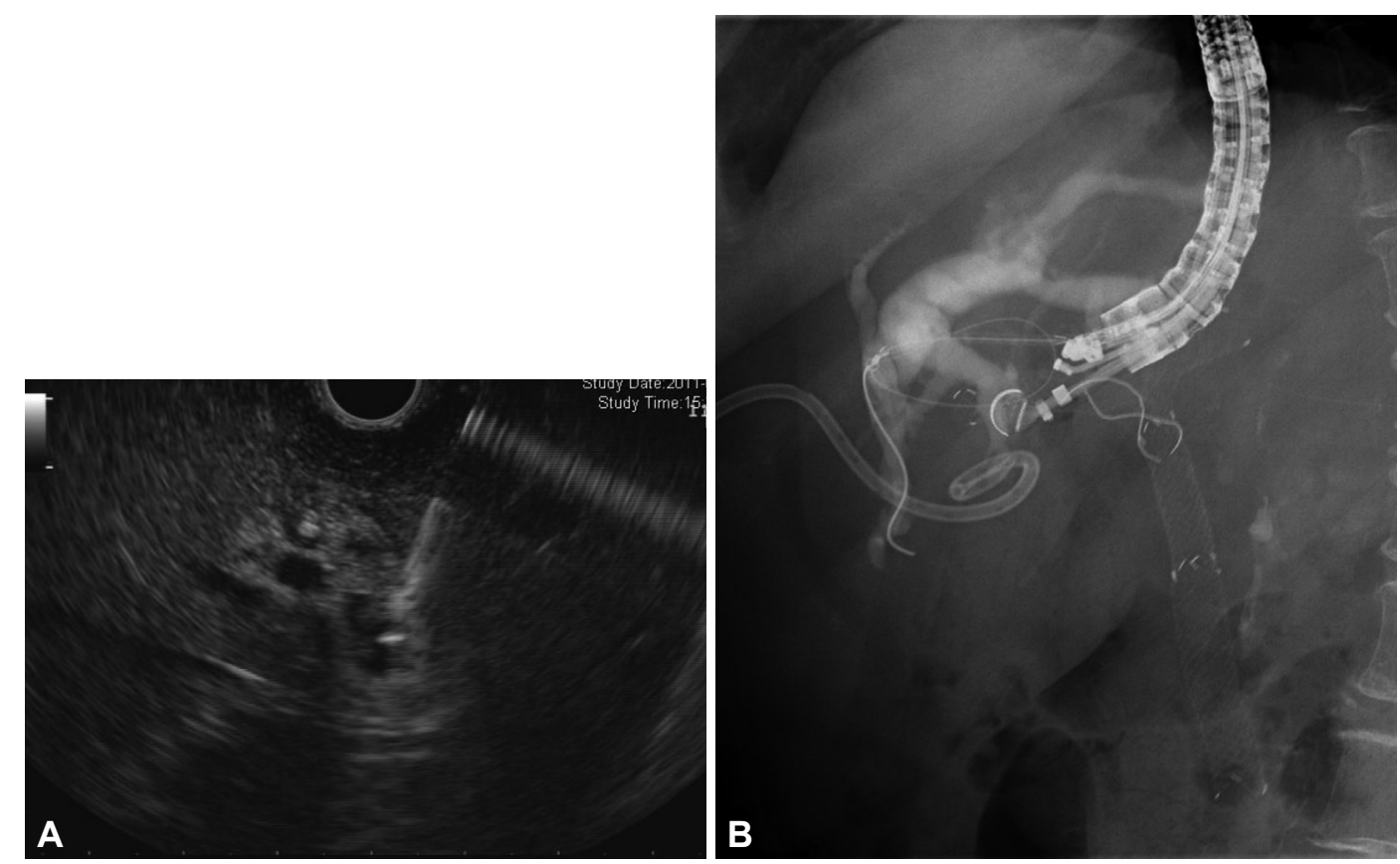

Fig. 3. Hepaticogastrostomy. Jaundice hadn't resolved after percutaneous and endoscopic drainage. Endoscopic ultrasonograpy-guided puncture of a dilated left intrahepatic duct $(A)$ and placement of metal stent $(B)$ was performed.

Table 1. Endoscopic Ultrasonograpy-guided Injection Therapy

\begin{tabular}{|c|c|c|c|}
\hline Material & Year & & Comment \\
\hline Cytoimplant ${ }^{39}$ (Mixed lymphocyte culture) & 2000 & Human & PR in $2 / 8$ patients, only one study \\
\hline $\begin{array}{l}\mathrm{ONYX}-015^{40} \text { (An E1B-55kD gene-deleted } \\
\text { replication-selective adenovirus) }\end{array}$ & 2003 & Human & $\begin{array}{l}\text { PR: } 2 / 21 \text { patients with gemcitabine, } 2 \text { sepsis and } \\
2 \text { duodenal perforation unrelated with ONYX-015 }\end{array}$ \\
\hline $\begin{array}{l}\text { TNFerade }{ }^{41-43} \\
\text { (Replication-deficient adenoviral vector with TNF- } \alpha \\
\text { gene and a radiation-inducible promoter Egr-1) }\end{array}$ & 2006 & Human & $\begin{array}{l}\text { Combination with radiation showed dose-related } \\
\text { responses in } 50 \text { patients (available only in abstract form, } \\
\text { no control). Phase } 2 / 3 \text { study is underway. }\end{array}$ \\
\hline $\begin{array}{l}\text { OncoGel }^{44,45} \text { (Continuous releasing paclitaxel } \\
\text { containing gel) }\end{array}$ & 2007 & Swine & Safe in 8 normal pigs \\
\hline Dendritic cell therapy ${ }^{46,47}$ & 2009 & Human & $\begin{array}{l}\text { Intra-tumoral injection combined with gemcitabine, } \\
\mathrm{PR} \text { in } 1 / 5 \text { patients }\end{array}$ \\
\hline $\begin{array}{l}\text { LC beads }^{48} \\
\text { (Continuous releasing irinotecan loaded } \\
\text { microspheres) }\end{array}$ & 2011 & Swine & Safe in 12 normal pigs \\
\hline
\end{tabular}

the generalized clinical application of ethanol ablation is deferred until well-organized clinical trials show real benefits to alter the natural history of pancreatic cysts. ${ }^{26}$

\section{EUS-GUIDED ABLATION THERAPY FOR SOLID PANCREATIC TUMOR}

Some recent studies have shown the feasibility of radiofrequency (RF) ablation in pancreatic cancer in an open, percutaneous or laparoscopic setting. ${ }^{27,28}$ However, RF ablation in the pancreas could be dangerous without cooling the adjacent tissue and real-time visualization of the ablation..$^{28-32} \mathrm{On}$ comparing techniques, EUS-guided ablation has some theoretical advantages such as it is less invasive than the surgical approach and more selective than the percutaneous approach. However it is still under experimentation in animal models. ${ }^{33-35}$ In animal models, the desirable ablation effect can be achieved by adjusting the time and energy delivered into porcine pancreas, but the complications such as pancreatitis or adhesion of the surrounding viscera have not been adequately evaluated to apply this technique to clinical fields. A more exact delineation of a lesion in $3 \mathrm{D}$ configuration and delicate adjustment of the ablation area may be helpful to improve the safety. 
Neuroendocrine tumor behaves more indolently than pancreatic cancer. Even in the case of metastasis, local debulking surgery and/or metastasectomy increases the survival of patients. Local ablation therapy with EUS-guided probe can theoretically be done. However, until now there were only a few anecdotal cases of EUS-guided ablation of neuroendocrine tumor. EUS-guided alcohol ablation of an insulinoma ${ }^{36}$ and the hepatic metastasis of insulinoma treated with percutaneous radio-frequency ablation ${ }^{37}$ were reported. EUS-guided ablation might be applied to high-risk patients.

\section{EUS-GUIDED INJECTION THERAPY}

Advanced pancreatic cancer has a dismal prognosis with the median survival being 3-4 months. Until now, no therapy has been proven to increase survival of these patients. Therefore, the main aim of therapy is to improve the quality of life.

Several investigational studies were conducted using EUSguided injection of various therapeutic agents, including various onco-viruses, ${ }^{38}$ chemotherapeutics and immune cells. After animal studies with swine pancreas, some of them were applied to patients. Unfortunately, no agent has currently shown an efficient tumor killing effect (Table 1).

The EUS-guided approach to pancreatic cancer from the stomach and duodenum is a potentially minimal invasive option for locally advanced cases, but the injected agents have not been so effective in patients with advanced pancreatic cancer.

\section{EUS-GUIDED PHOTODYNAMIC THERAPY}

Following the infusion of photosensitizing drug, target tissue necrosis can be induced by exposure to light of a proper wavelength. EUS-guided fine-needle aspiration technique can be used for delivery of a light source to pancreatic cancer. The feasibility of this therapy was tested in a healthy swine model. ${ }^{39,40}$ There were no serious complications and there was proper tissue necrosis. Further studies that will consider the cost-effectiveness and biology of pancreatic cancer are needed for this therapy.

\section{EUS-GUIDED FIDUCIAL PLACEMENT}

A fiduciary marker or fiducial is an object used as a point of reference in external beam radiation therapy. Only gold fiducials are available to facilitate stereotactic body radiotherapy (SBRT) for the treatment of locally advanced pancreatic cancer. Placement of gold fiducials in the lesions is performed with EUS-guided delivery through a 19-guage needle, ${ }^{41-44}$ which enables a high-dose therapeutic beam of radiation to reach the tumor. The technique to push fiducials to go through the curved pathway is a technical challenge. The stylet-push method or the sterile water-push method is used. ${ }^{44}$ The successful placement and SBRT were done in around $90 \%$ of patients. ${ }^{43,44}$ The fiducials migrated in less than $5 \%$ without complication. To define their clinical usefulness, fiducial placement should be compared with conventional radiation therapy in prospective randomized blinded trials.

\section{EUS-GUIDED BRACHYTHERAPY}

Intraoperative interstitial brachytherapy has showed some beneficial effects for the local control of malignant pancreatic tumors. During operation, radioactive seeds placed in the pancreatic tumors emit steady gamma rays that lead to local ablation. EUS is used to place radioactive materials into the pancreas without laparotomy. Iodine-125 radioactive seeds were inserted through a 19-guage needle. ${ }^{45,46}$ In a pilot study, a partial response of unresectable pancreatic cancer was observed in $26.7 \%$ (4/15 patients) with limited improvement of pain. Only minor complications were reported in this study and in some porcine models. ${ }^{47}$ Complications such as fistula formation, gastrointestinal bleeding, ascending cholangitis and intrahepatic cyst formation were reported in operative settings. ${ }^{48}$ Considering the nature of pancreatic cancer and risk/benefits of brachytherapy, the precise role of this modality should be carefully investigated.

\section{CONCLUSIONS}

EUS-guided therapy is a new frontier for endoscopists. EUS-guided pseudocyst drainage and celiac plexus neurolysis and block can be recommended as a standard treatment if they are indicated. The others are under investigation and some of them showed promising results. Further progress of technology will make interventional EUS more useful for treating pancreatico-biliary diseases and well-designed clinical trials will clarify the role of investigational EUS-guided therapies.

\section{Conflicts of Interest}

The authors have no financial conflicts of interest.

\section{REFERENCES}

1. Sauer B, Kahaleh M. Prospective randomized trial comparing EUS and EGD for transmural drainage of pancreatic pseudocysts: a need for a large randomized study. Gastrointest Endosc 2010;71:432.

2. Varadarajulu S, Christein JD, Tamhane A, Drelichman ER, Wilcox CM. Prospective randomized trial comparing EUS and EGD for transmural drainage of pancreatic pseudocysts (with videos). Gastrointest Endosc 2008;68:1102-1111. 
3. Krüger M, Schneider AS, Manns MP, Meier PN. Endoscopic management of pancreatic pseudocysts or abscesses after an EUS-guided 1-step procedure for initial access. Gastrointest Endosc 2006;63:409-416.

4. Lopes CV, Pesenti C, Bories E, Caillol F, Giovannini M. Endoscopic-ultrasound-guided endoscopic transmural drainage of pancreatic pseudocysts and abscesses. Scand J Gastroenterol 2007;42:524-529.

5. Antillon MR, Shah RJ, Stiegmann G, Chen YK. Single-step EUS-guided transmural drainage of simple and complicated pancreatic pseudocysts. Gastrointest Endosc 2006;63:797-803.

6. Eisenberg E, Carr DB, Chalmers TC. Neurolytic celiac plexus block for treatment of cancer pain: a meta-analysis. Anesth Analg 1995;80:290295.

7. Puli SR, Reddy JB, Bechtold ML, Antillon MR, Brugge WR. EUS-guided celiac plexus neurolysis for pain due to chronic pancreatitis or pancreatic cancer pain: a meta-analysis and systematic review. Dig Dis Sci 2009;54:2330-2337.

8. Santosh D, Lakhtakia S, Gupta R, et al. Clinical trial: a randomized trial comparing fluoroscopy guided percutaneous technique vs. endoscopic ultrasound guided technique of coeliac plexus block for treatment of pain in chronic pancreatitis. Aliment Pharmacol Ther 2009;29:979-984.

9. Gress F, Schmitt C, Sherman S, Ikenberry S, Lehman G. A prospective randomized comparison of endoscopic ultrasound- and computed tomography-guided celiac plexus block for managing chronic pancreatitis pain. Am J Gastroenterol 1999;94:900-905.

10. Bories E, Pesenti C, Caillol F, Lopes C, Giovannini M. Transgastric endoscopic ultrasonography-guided biliary drainage: results of a pilot study. Endoscopy 2007;39:287-291.

11. Belletrutti PJ, DiMaio CJ, Gerdes H, Schattner MA. Endoscopic ultrasound guided biliary drainage in patients with unapproachable ampullae due to malignant duodenal obstruction. J Gastrointest Cancer 2011; 42:137-142.

12. Brauer BC, Chen YK, Fukami N, Shah RJ. Single-operator EUS-guided cholangiopancreatography for difficult pancreaticobiliary access (with video). Gastrointest Endosc 2009;70:471-479.

13. Itoi T, Itokawa F, Sofuni A, et al. Endoscopic ultrasound-guided choledochoduodenostomy in patients with failed endoscopic retrograde cholangiopancreatography. World J Gastroenterol 2008;14:6078-6082.

14. Will U, Thieme A, Fueldner F, Gerlach R, Wanzar I, Meyer F. Treatment of biliary obstruction in selected patients by endoscopic ultrasonography (EUS)-guided transluminal biliary drainage. Endoscopy 2007;39: 292-295.

15. Yamao K, Sawaki A, Takahashi K, Imaoka H, Ashida R, Mizuno N. EUS-guided choledochoduodenostomy for palliative biliary drainage in case of papillary obstruction: report of 2 cases. Gastrointest Endosc 2006;64:663-667.

16. Will U, Fueldner F, Thieme AK, et al. Transgastric pancreatography and EUS-guided drainage of the pancreatic duct. J Hepatobiliary Pancreat Surg 2007;14:377-382

17. Kahaleh M, Hernandez AJ, Tokar J, Adams RB, Shami VM, Yeaton P. EUS-guided pancreaticogastrostomy: analysis of its efficacy to drain inaccessible pancreatic ducts. Gastrointest Endosc 2007;65:224-230

18. Kahaleh M, Wang P, Shami VM, Tokar J, Yeaton P. EUS-guided transhepatic cholangiography: report of 6 cases. Gastrointest Endosc 2005; 61:307-313.

19. Mallery S, Matlock J, Freeman ML. EUS-guided rendezvous drainage of obstructed biliary and pancreatic ducts: report of 6 cases. Gastrointest Endosc 2004;59:100-107.

20. Trevino JM, Varadarajulu S. Initial experience with the prototype forward-viewing echoendoscope for therapeutic interventions other than pancreatic pseudocyst drainage (with videos). Gastrointest Endosc 2009;69:361-365.

21. Gan SI, Thompson CC, Lauwers GY, Bounds BC, Brugge WR. Ethanol lavage of pancreatic cystic lesions: initial pilot study. Gastrointest Endosc 2005;61:746-752.

22. DeWitt J, McGreevy K, Schmidt CM, Brugge WR. EUS-guided ethanol versus saline solution lavage for pancreatic cysts: a randomized, doubleblind study. Gastrointest Endosc 2009;70:710-723.

23. DiMaio CJ, DeWitt JM, Brugge WR. Ablation of pancreatic cystic lesions: the use of multiple endoscopic ultrasound-guided ethanol lavage sessions. Pancreas 2011;40:664-668.

24. Oh HC, Seo DW, Lee TY, et al. New treatment for cystic tumors of the pancreas: EUS-guided ethanol lavage with paclitaxel injection. Gastrointest Endosc 2008;67:636-642.

25. Oh HC, Seo DW, Song TJ, et al. Endoscopic ultrasonography-guided ethanol lavage with paclitaxel injection treats patients with pancreatic cysts. Gastroenterology 2011;140:172-179.

26. ASGE Technology Committee, Kaul V, Adler DG, et al. Interventional EUS. Gastrointest Endosc 2010;72:1-4.

27. Wu Y, Tang Z, Fang H, et al. High operative risk of cool-tip radiofrequency ablation for unresectable pancreatic head cancer. J Surg Oncol 2006;94:392-395.

28. Spiliotis JD, Datsis AC, Michalopoulos NV, et al. High operative risk of cool-tip radiofrequency ablation for unresectable pancreatic head cancer. J Surg Oncol 2007;96:89-90.

29. Elias D, Baton O, Sideris L, Lasser P, Pocard M. Necrotizing pancreatitis after radiofrequency destruction of pancreatic tumours. Eur J Surg Oncol 2004;30:85-87.

30. Matsui Y, Nakagawa A, Kamiyama Y, Yamamoto K, Kubo N, Nakase Y. Selective thermocoagulation of unresectable pancreatic cancers by using radiofrequency capacitive heating. Pancreas 2000;20:14-20.

31. Siriwardena AK. Radiofrequency ablation for locally advanced cancer of the pancreas. JOP 2006;7:1-4.

32. Spiliotis JD, Datsis AC, Michalopoulos NV, et al. Radiofrequency ablation combined with palliative surgery may prolong survival of patients with advanced cancer of the pancreas. Langenbecks Arch Surg 2007; 392:55-60.

33. Carrara S, Arcidiacono PG, Albarello L, et al. Endoscopic ultrasoundguided application of a new hybrid cryotherm probe in porcine pancreas: a preliminary study. Endoscopy 2008;40:321-326.

34. Brugge WR. EUS-guided tumor ablation with heat, cold, microwave, or radiofrequency: will there be a winner? Gastrointest Endosc 2009;69(2 Suppl):S212-S216.

35. Goldberg SN, Mallery S, Gazelle GS, Brugge WR. EUS-guided radiofrequency ablation in the pancreas: results in a porcine model. Gastrointest Endosc 1999;50:392-401.

36. Jürgensen C, Schuppan D, Neser F, Ernstberger J, Junghans U, Stölzel U. EUS-guided alcohol ablation of an insulinoma. Gastrointest Endosc 2006;63:1059-1062.

37. Scott A, Hinwood D, Donnelly R. Radio-frequency ablation for symptom control in a patient with metastatic pancreatic insulinoma. Clin Endocrinol (Oxf) 2002;56:557-559.

38. Kasuya H, Takeda S, Nomoto S, Nakao A. The potential of oncolytic virus therapy for pancreatic cancer. Cancer Gene Ther 2005;12:725-736.

39. Yusuf TE, Matthes K, Brugge WR. EUS-guided photodynamic therapy with verteporfin for ablation of normal pancreatic tissue: a pilot study in a porcine model (with video). Gastrointest Endosc 2008;67:957-961.

40. Chan HH, Nishioka NS, Mino M, et al. EUS-guided photodynamic therapy of the pancreas: a pilot study. Gastrointest Endosc 2004;59:9599.

41. Pishvaian AC, Collins B, Gagnon G, Ahlawat S, Haddad NG. EUSguided fiducial placement for CyberKnife radiotherapy of mediastinal and abdominal malignancies. Gastrointest Endosc 2006;64:412-417.

42. Savides TJ. EUS-guided fine-needle insertion of radiopaque fiducials: X marks the spot. Gastrointest Endosc 2006;64:418-419.

43. Sanders MK, Moser AJ, Khalid A, et al. EUS-guided fiducial placement for stereotactic body radiotherapy in locally advanced and recurrent pancreatic cancer. Gastrointest Endosc 2010;71:1178-1184.

44. Park WG, Yan BM, Schellenberg D, et al. EUS-guided gold fiducial insertion for image-guided radiation therapy of pancreatic cancer: 50 successful cases without fluoroscopy. Gastrointest Endosc 2010;71:513- 
518.

45. Sun S, Xu H, Xin J, Liu J, Guo Q, Li S. Endoscopic ultrasound-guided interstitial brachytherapy of unresectable pancreatic cancer: results of a pilot trial. Endoscopy 2006;38:399-403.

46. Jin Z, Du Y, Li Z, Jiang Y, Chen J, Liu Y. Endoscopic ultrasonographyguided interstitial implantation of iodine 125-seeds combined with chemotherapy in the treatment of unresectable pancreatic carcinoma: a prospective pilot study. Endoscopy 2008;40:314-320.

47. Sun S, Qingjie L, Qiyong G, Mengchun W, Bo Q, Hong X. EUS-guided interstitial brachytherapy of the pancreas: a feasibility study. Gastrointest Endosc 2005;62:775-779.

48. Order SE, Siegel JA, Principato R, et al. Selective tumor irradiation by infusional brachytherapy in nonresectable pancreatic cancer: a phase I study. Int J Radiat Oncol Biol Phys 1996;36:1117-1126. 